Research Paper

\title{
Comparison of methods for the detection of biofilm formation by Staphylococcus aureus isolated from bovine subclinical mastitis
}

\author{
Poliana de Castro Melo ${ }^{1}$, Luciano Menezes Ferreira ${ }^{1}$, Antônio Nader Filho ${ }^{1}$, \\ Luiz Francisco Zafalon ${ }^{2}$, Hinig Isa Godoy Vicente ${ }^{3}$, Viviane de Souza ${ }^{4}$ \\ ${ }^{1}$ Departamento de Medicina Veterinária Preventiva, \\ Universidade Estadual Paulista "Júlio de Mesquita Filho", Jaboticabal, SP, Brazil. \\ ${ }^{2}$ Embrapa Pecuária Sudeste, São Carlos, SP, Brazil. \\ ${ }^{3}$ Secretaria da Agricultura do Estado de São Paulo, Jaboticabal, SP, Brazil. \\ ${ }^{4}$ Embrapa Caprinos e Ovinos, Sobral, CE, Brazil.
}

Submitted: April 21, 2011; Approved: July 2, 2012.

\begin{abstract}
Biofilm formation is considered to be a selective advantage for Staphylococcus aureus mastitis isolates by facilitating bacterial persistence in the udder. It requires attachment to mammary epithelium, proliferation and accumulation of cells in multilayers. The objective of this study was to determine the sensitivity and specificity of three techniques for the detection of $S$. aureus biofilm-positive strains. Two phenotypic tests, including growth on microtitre plates and Congo red agar, were compared with a PCR technique using 94 S. aureus strains obtained from cows with subclinical mastitis from two farms in the state of São Paulo. These strains were characterised by in vitro slime production on Congo red agar, biofilm formation on microtitre plates and the presence of the icaA and icaD genes. The results revealed that $85 \%$ of the isolates tested produced slime on the Congo red agar, $98.9 \%$ of the isolates produced biofilms in vitro by adhering to sterile $96-w e l l$ "U" bottom polystyrene tissue culture plates, and $95.7 \%$ of the isolates carried the ica $\mathrm{A}$ and $i c a \mathrm{D}$ genes. The results of the phenotypic tests for biofilm formation were compared with those of the molecular analysis, and the sensitivity and specificity of the Congo red agar test were $88.9 \%$ and $100 \%$, respectively, while those of the microtitre plate test were $100 \%$ and $25 \%$, respectively. When the phenotypic methods for the detection of biofilm producers, namely growth on microtitre plates and Congo red agar, were compared, the sensitivity and specificity were $86 \%$ and $100 \%$, respectively. Therefore, growth on Congo red agar and the microtitre plate test are methods that could be used to determine whether an isolate has the potential for biofilm production.
\end{abstract}

Key words: biofilms, bovine mastitis, phenotypic and molecular analysis, Staphylococcus aureus.

\section{Introduction}

Staphylococcus aureus is an important etiologic agent of intramammary infections in ruminants and, most $S$. aureus strains associated with mastitis are found surrounded by a layer of slime. This layer allows the pathogen to adhere to and colonise the host mammary gland epithelium (Baselga et al., 1993; Bergey \& Holt, 1994; Aguilar \& Iturralde, 2001).
The two methods broadly used for the phenotypic identification of biofilm-producing strains are the microtitre-plate test (MtP) (Christensen et al., 1985; Christensen, 1989) and the Congo red agar (CRA) test (Freeman et al., 1989). The MtP was developed to replace the test tube method, which was the first method used for macroscopic estimation of bacterial biofilm on the surface of plastic tubes. The microtitre-plate technique uses a 96-well-plate spectrophotometer to measure the optical density (O.D.) of stained bacterial biofilms found on the bottom of tissue cul-

Send correspondence to P.C. Melo. Departamento de Medicina Veterinária Preventiva Universidade Estadual Paulista "Júlio de Mesquita Filho", Jaboticabal, SP, Brazil. E-mail: policame@yahoo.com.br. 
ture plates and produces quantitative results (Stepanovic et al., 2000; Arciola et al., 2005).

The CRA plate test uses a solid medium, namely Congo red agar. This method allows for the direct analysis of the colonies and the identification of slime-forming strains (which appear as black colonies on the red agar) and non-slime-forming strains (red-coloured colonies). This is not a quantitative assay because it is based on a subjective chromatic evaluation. The strains that score positive during the test have black spikes on red colonies which remain unchanged in colour (Freeman et al., 1989).

The implications of biofilm formation for infections and drug resistance have triggered an increased interest in the characterisation of the genes involved in biofilm formation. The intercellular adhesion (ica) locus consists of the genes ica $\mathrm{ADBC}$, and among the ica genes, ica $\mathrm{A}$ and $i c a \mathrm{D}$ have been reported to play a significant role in biofilm formation in S. aureus and S. epidermidis (Cramton et al., 1999).

Molecular techniques have recently been used for detecting the genes responsible for the slime exopolysaccharide component of biofilms, also known as polysaccharide intercellular adhesin (PIA). PIA is made up of a linear 1,6-linked glycosaminoglycan and synthesised in vitro from UDP- $N$-acetylglucosamine by $N$-acetylglucosaminyltransferase, which is encoded by the intercellular adhesion (ica) locus, specifically by the icaA gene. Coexpression of ica $\mathrm{A}$ and $i c a \mathrm{D}$ genes leads to the full phenotypic expression of the capsular polysaccharide (Vasudevan et al., 2003).

Early detection and management of potentially pathogenic staphylococci is an essential step towards prevention and management of bovine mastitis. Therefore, there is a need to evaluate a simple and cheap method for the detection of biofilm producers. Biofilm production can be a marker of virulence and, can be detected by phenotypic assays (Baselga et al., 1993; Dhanawade et al., 2010).

Herein, we evaluated strains of $S$. aureus isolated from cows with subclinical mastitis by the CRA, MtP and PCR analysis. Our aim was to determine the efficacy of each of the phenotypic tests using the PCR test as the gold standard. We also compared the two phenotypic tests (MtP and CRA) each other using the MtP as the standard. The results obtained were used to review and compare the efficacy of three different detection assays for the diagnosis of biofilm staphylococci mastitis.

\section{Materials and Methods}

\section{Bacterial strains and storage}

Ninety-four $S$. aureus strains were isolated from milk samples collected from dairy cows with subclinical mastitis in two herds in the state of São Paulo. The strains were collected monthly during 12 months, from 2001 until 2002 for the first dairy herd and from 2005 until 2006 for the second dairy herd. The staphylococcal species was identified by biochemical test (Bergey \& Holt, 1994; MacFaddin, 1976) and confirmed by PCR analysis (Martineau et al., 1998). The biofilm-producer ATCC 25923 and the biofilm negative ATCC 12228 were used as reference strains.

\section{Phenotypic characterization of biofilm formation by microtitre plate test}

Microtitre-plate test was modified (Cucarella et al., 2001). The modification was related with the dilution that according to the author was 1:40 (Cucarella et al., 2001) and in this research the dilution was 1:200. Overnight cultures were diluted 1:200 with Trypticase Soy Broth (TSB, BD,NJ Franklin Lakes) containing $0.25 \%$ glucose, and $200 \mu \mathrm{L}$ per well were seeded in sterile 96 -well polystyrene tissue culture plates at $37^{\circ} \mathrm{C}$ for $18 \mathrm{~h}$. After three washes in phosphate buffered saline solution ( $\mathrm{pH} 7.2)$, wells were dried for $1 \mathrm{~h}$ at $60^{\circ} \mathrm{C}$ and the adherent biofilms were stained with $1 \%$ crystal violet for one minute. After rinsing three times with distilled water and subsequent drying at room temperature, the absorbance of the adherent biofilm was measured at $490 \mathrm{~nm}$ in a microplate reader (Thermoplate reader, Brasil). Uninoculated wells containing TSB with glucose served as blanks. The blank corrected absorbance values of $S$. aureus strains were used for reporting biofilm production. Strains producing a blank corrected mean absorbance value of $>0.1$ were considered as weak biofilm producers, and if the value was higher than 1.0 its was considered a higher biofilm producer. (Mack et al., 2000). Each strain was tested for biofilm production in duplicates and the assay was repeated three times.

\section{Phenotypic characterization of biofilm production in CRA}

The strains were cultured on CRA plates, prepared by adding $0.8 \mathrm{~g}$ of Congo red and $36 \mathrm{~g}$ of saccharose (both from Sigma, Missouri, EUA) to $1 \mathrm{~L}$ of BHI (Oxoid, Basingstoke, Hampshire, England). The plates were subsequently incubated for $24 \mathrm{~h}$ at $37^{\circ} \mathrm{C}$ and overnight at room temperature. The production of rough black colonies by slime producing strains was used to differentiate them from non-slime producing $S$. aureus strains (red smooth colonies) (Freeman et al., 1989).

\section{PCR method for the identification of icaA and icaD genes responsible for PIA synthesis}

\section{Isolation of genomic DNA}

S. aureus chromosomal DNA isolates were extracted with GFX kit genomic blood (Amersham Biosciences, England).

\section{PCR}

The primers for the amplification of $i c a \mathrm{~A}$ and $i c a \mathrm{D}$ genes were designed from the published sequence of the ica 
locus described by Cramton et al. (1999). For the detection of icaA, primers ICAAF (TCT CTT GCA GGA GCA ATC AA) and ICAAR (TCA GGC ACT AAC ATC CAG CA) were used to amplify a $188 \mathrm{bp}$ fragment. Similarly for amplifying icaD, primers ICADF (ATG GTC AAG CCC AGA CAG AG) and ICADR (CGT GTT TTC AAC ATT TAA TGC AA) were used for a 198 bp fragment. A $20 \mu \mathrm{L}$ reaction volume consisted of $2.5 \mathrm{mM} \mathrm{MgCl} 2,200 \mathrm{mM}$ of each nucleotide, $1 \mathrm{mM}$ of each primer, $1.25 \mathrm{U}$ of Taq polymerase and $100 \mathrm{ng}$ of template DNA. Thirty cycles of amplification, each consisting of denaturation at $92{ }^{\circ} \mathrm{C}$ for $45 \mathrm{~s}$, annealing at $49^{\circ} \mathrm{C}$ for $45 \mathrm{~s}$ and elongation at $72^{\circ} \mathrm{C}$ for $1 \mathrm{~min}$, along with a final extension at $72{ }^{\circ} \mathrm{C}$ for $7 \mathrm{~min}$ were performed in a thermocycler (Eppendorf, USA). The presence and size of the amplified products were confirmed by electrophoresis on $1.5 \%$ agarose gel.

\section{Statistical analysis}

Statistical analysis was performed using SAS software 2002 (SAS, 2001). The test was used for comparison of sensitivity, specificity, kappa, positive predictive value (PPV) and negative predictive value (NPV) of CRA and MtP method calculated by using Test Diag (Godoy, 1999) (analysis of 22 table). MtP method was used as standard. And for the analysis of CRA and icaAD genes and MtP and icaAD genes, the molecular analysis (presence of icaAD genes) was used as gold standard.

\section{Results}

\section{Detection of biofilm production phenotype by microtitre plate test}

The microtitre plate test correctly identify both the positive and the negative reference bacterial strains. Ninety-three out of 94 strains $(98.9 \%)$ were found to be biofilm producers. Only 1 strain was found to be negative by both the microtitre plate test and CRA test, and this strain lacked the ica $\mathrm{AD}$ genes indicating, it was a biofilm non-producer.

\section{Detection of the biofilm-producing phenotype by the Congo Red Agar test (CRA)}

A total of $85 \%$ of the strains $(n=80)$ were producers of rough black colonies, and 15\% strains (Freeman et al., 1989) were classified as non-producers (smooth red colonies). The two reference strains, ATCC 25923 and ATCC 12228 , were found to be positive and negative, as expected.

\section{PCR detection of icaA and icaD}

Ninety strains (95\%) were positive by PCR for both ica $\mathrm{A}$ and ica $\mathrm{D}$ genes, as indicated by the sizes of the PCR bands observed (188 bp for icaA and $198 \mathrm{bp}$ for icaD), whereas four strains were negative by PCR. All of the slime-producing strains were positive for both genes. Among non slime producers, 10 were positive for ica genes, which may indicate that these strains actually have the ability to produce slime. All samples that were PCR negative were also negative in the CRA test. Eighty-nine strains $(94.6 \%)$ were biofilm-producers in the microtitre plate test, which were also positive by PCR. Three isolates tested positive as biofilm-producers in the microtitre plate test but were negative by PCR (Table 1).

\section{Discussion}

The ability of $S$. aureus to form biofilms helps the bacterium to survive in hostile environments within the host and is considered to be responsible for chronic or persistent infections (Christensen et al., 1985; Bernardi et al., 2007). Several studies have shown that the formation of slime and biofilms by $S$. aureus and $S$. epidermidis strains causing catheter-associated and nosocomial infections is associated with the presence of the icaA and icaD genes (Ziebuhr et al., 1997; Arciola et al., 2001, 2002). In this research, the results of a PCR test for the ica A and icaD genes and phenotypic tests were important to foment studies on mastitis and develop diagnostic tests for biofilm-producing microorganisms.

The Microtitre plate test is a convenient and economical quantitative technique for the identification of critical factors and optimal culture conditions for biofilm forma-

Table 1 - Phenotypic characterisation by CRA and microtitre plate test and genotypic identification on ica genes from 94 S. aureus strains isolated from the milk of cows with subclinical mastitis in São Paulo state.

\begin{tabular}{llccc}
\hline CRA & Microtitre Test & Presence of $i c a$ A gene & Presence of $i c a \mathrm{D}$ gene & Isolates of $S$. aureus $\%$ \\
\hline Black & Strong Adherence & Positive & Positive & $75(79.7)$ \\
Black & Strong Adherence & Positive & Positive & $5(5.4)$ \\
Red & Weak Adherence & Positive & Positive & $1(1.1)$ \\
Red & Negative & Negative & Negative & $1(1.1)$ \\
Red & Strong adherence & Positive & Positive & $7(7.5)$ \\
Red & Strong adherence & Negative & Negative & $3(3.1)$ \\
Red & Strong adherence & Positive & Positive & $2(2.1)$ \\
Total & - & - & - & $94 / 94$ \\
\hline
\end{tabular}


tion. This technique is used for direct detection of polysaccharide production because spectrophotometric measurements provide quantitative information on the ability of bacterial strains to rapidly grow while adhering to the substratum. However, it can be less accurate in determining their specific ability to secrete PIA because, while it is a very sensitive test, it has low specificity (Stepanovic et al., 2000).

Previously, the results of CRA test and the adherence to microplates test (MtP) were compared with the presence of the ica $\mathrm{A}$ and icaD genes for strains of Staphylococcus epidermidis isolated from medical implants, and the genotypic test was used as the gold standard (Baselga et al., 1993; Arciola et al., 2005). The authors found that $57 \%$ of the strains were positive for the $i c a \mathrm{~A}$ and $i c a \mathrm{D}$ genes, and three of these strains were negative by the CRA test. It was also verified that $16 \%$ of the $66 \%$ strains that produced biofilms in the MtP test were negative for ica $\mathrm{A}$ and ica $\mathrm{D}$ by PCR. In total, $10 \%$ of the $16 \%$ of biofilm-positive strains that were ica $\mathrm{A}$ and ica $\mathrm{D}$ negative were classified as weak producers of biofilms (weak adherence). The presence of the genes was best correlated with a positive CRA test (Baselga et al., 1993; Arciola et al., 2005; Jain \& Agarwal, 2009).

In this study, the microtitre test allowed an easy and quantitative classification of the staphylococcal isolates. Matching results from both CRA and Microtitre plate test were obtained with $81(87 \%)$ of the strains screened. Among the 94 strains tested, a low correlation was found between the results of the PCR-based analysis and the CRA test. This finding indicates that the CRA test produces a high number of false negatives.

The CRA test identified $100 \%$ of the negative biofilm producer strains, and $28.6 \%$ of the strains identified as negative by the CRA test were actually negative, based on a negative predictive value (NPV) calculation. In total, $88.9 \%$ of the strains were positive for the production of biofilm, and the probability that they were actually positive was $100 \%$, based on a positive predictive value (PPV) calculation. Due to the number of false negative results, the negative predictive value was low which indicates reduced sensitivity. However, this test was very specific, even thought it had a low NPV (Table 2). According to the author who developed the CRA test, polysaccharides are the target of the dye. In his article, he described the use of the Congo red dye to verify the presence of polysaccharides on gram negative bacteria of aquatic origin under a light microscope. Using the dye, he was able to verify that the polysaccharides on the bacilli and the staphylococci had a similar staining pattern (Freeman et al., 1989).

In this study, the colour scale for the CRA test, which has been reported previously, was not changed (Ziebuhr et al., 2001). Therefore, plates that had colonies of indeterminate colour (e.g., those that were dark red but were tending towards black) were repeated. Another variable that was
Table 2 - Comparison of results between ica $\mathrm{A}$ and ica $\mathrm{D}$ gene expression and CRA tests on $S$. aureus strains isolated from milk associated with bovine subclinical mastitis during the period from 2001 until 2006.

\begin{tabular}{lcccc}
\hline Staphylococcus aureus & \multicolumn{4}{c}{ PCR (icaA and icaD) } \\
\cline { 2 - 5 } Congo red agar (CRA) & Positive & Negative & Total & $\%$ \\
\hline Positive & 80 & 0 & 80 & 85.10 \\
Negative & 10 & 4 & 14 & 14.90 \\
Total & 90 & 4 & 94 & 100 \\
\hline
\end{tabular}

Sensitivity - $89 \%$.

Specificity $-100 \%$.

Positive predictive value (PPV) - $100 \%$.

Negative predictive value (NPV) $-28.60 \%$.

Kappa: 0.41 and $\mathrm{p}<0.05$.

tested was the use of sucrose. In some articles, the authors used glucose instead of sucrose, but in the present research, the results were similar for glucose and sucrose (Freeman et al., 1989; Jain \& Agarwal, 2009).

The results of the microtitre plate test were compared with those of the CRA test, and the results of the microtitre plate test indicate that it was better than the CRA test in the detection of biofilms in vitro, because of it's a higher sensitivity $(100 \%)$, in detecting the positive strains. Therefore, the microtitre plate test is recommended for routine analysis of strains of $S$. aureus isolated from samples of milk. This test also had a better correlation with the presence of ica AD by PCR, which is correlated with the detection of the intercellular polysaccharide that is the major component of biofilm (Table 3).

In a previous study, the microtitre plate test (MtP) and CRA assay were used to identify Staphylococci biofilmproducing strains, using the MtP as the gold standard, and it was determined that the sensitivity and specificity of the Congo red agar assay were $90.63 \%$ and $90.6 \%$, respectively, for the detection of $S$. aureus biofilm producers (Jain \& Agarwal, 2009). In the present research, the samples were placed on the same microplate in duplicate, and the test was repeated three times. All of the results were very similar; therefore, there was no need to perform the test in triplicate or quadruplicate. We did not test different con-

Table 3 - Comparison of results from icaA and icaD gene expression and microtitre plate tests on $S$. aureus strains isolated from milk associated with bovine subclinical mastitis during the period from 2001 until 2006.

\begin{tabular}{lcccc}
\hline Staphylococcus aureus & \multicolumn{4}{c}{ PCR (icaA and icaD) } \\
\cline { 2 - 5 } Microtitre plate test (MtP) & Positive & Negative & Total & $\%$ \\
\hline Positive & 90 & 3 & 93 & 98.9 \\
Negative & 0 & 1 & 1 & 1.1 \\
Total & 90 & 4 & 94 & 100 \\
\hline
\end{tabular}

Sensitivity $-100 \%$.

Specificity $-25 \%$.

Positive predictive value (PPV) - 96.70\%.

Negative predictive value (NPV) - $100 \%$.

Kappa: 0.39 and $\mathrm{p}<0.05$. 
centrations of sugars because $98 \%$ of the samples produced biofilms in the microtitre plate test.

In this study, we also compared the results from the CRA and MtP tests using the MtP test as the gold standard, and the results revealed that the sensitivity and the specificity of the CRA test were $86 \%$ and $100 \%$, respectively. These results suggest that the CRA test could be successfully used to detect $S$. aureus biofilm-producing strains, but when the CRA and MtP tests were compared with the molecular analysis, the results indicated that the MtP test should be the first choice because this test was more sensitive than the CRA test, identifying all of the biofilm positive strains (Table 4). The Congo red agar test has been previously compared to the microtitre plate test, which was considered to be the gold standard, in a report by Jain and colleagues (2009) published in the Journal of Microbiological Methods (Stepanovic et al., 2000; Jain \& Agarwal, 2009).

The presence of the ica locus in $95 \%$ of the mastitis $S$. aureus isolates confirms its potential role as a virulence factor in the pathogenesis of mastitis in ruminants. Several studies have reported a higher frequency of distribution of the ica locus in clinical isolates of $S$. epidermidis than in saprophytic strains, emphasising its utility as a virulence marker (Christensen, 1989; Costerton et al., 1999; Ziebuhr et al., 2001; Arciola et al., 2001, 2002). The biofilm formation by strains that did not have the ica genes in this study could be explained by the presence of other genes, such as bap, which can compensate for a deficiency of ica genes. According to other studies, the $b a p$ gene in strains isolated from the bovine intramammary gland facilitated biofilm formation and the persistence of S. aureus (Cucarella et al., 2001). In the present research, the bap gene was not studied.

In a previous study detecting $S$. aureus biofilm producers associated with bovine mastitis, the authors verified that the PCR technique reliably identified the biofilmproducing potential of $S$. aureus strains, which may help in the rapid detection of biofilm-producing Staphylococci. The best correlation of the PCR test with phenotypic tests

Table 4 - Comparison of results from CRA and Microtitre plate test on $S$. aureus strains isolated from milk associated with bovine subclinical mastitis during the period from 2001 until 2006.

\begin{tabular}{lcccc}
\hline \multirow{2}{*}{ Staphylococcus aureus } & \multicolumn{4}{c}{ Microtitre plate test (MtP) } \\
\cline { 2 - 5 } Congo red agar (CRA) & Positive & Negative & Total & $\%$ \\
\hline Positive & 80 & 0 & 80 & 85.1 \\
Negative & 13 & 1 & 14 & 14.9 \\
Total & 93 & 1 & 94 & 100 \\
\hline
\end{tabular}

Sensitivity - $86 \%$.

Specificity $-100 \%$

Positive predictive value (PPV) - $100 \%$.

Negative predictive value (NPV) $-7.1 \%$.

Kappa: 0.12 and $\mathrm{p}<0.05$. occurred with the CRA assay and the microtitre plate test (MtP). In this research, the CRA and microtitre plate tests showed results that were significantly correlated with the molecular analysis (Dhanawade et al., 2010).

The ability of Staphylococcus aureus to produce biofilm is an important factor affecting the long-term persistence of the bacteria in the mammary gland and can result in chronic mastitis and decreased efficacy of antibiotic therapy. Virulent S. aureus strains can be identified by the presence of genes participating in biofilm formation. However, PCR analysis only reveals the genetic predisposition for biofilm formation and expression of ica genes thus, the real biofilm formation must be confirmed by additional phenotypic methods.

\section{Conclusion}

The MtP method presents higher sensitivity when compared with molecular analysis to identify $S$. aureus biofilm producers. The CRA method should be used as a complementary test because of the higher specificity relative to the MtP method. All of the methods were effective at detecting $S$. aureus biofilm-producing strains, and the two classic phenotypic tests can be reliably used to detect biofilm-producing strains because they are acceptably sensitive and specific.

\section{Acknowledgments}

The authors thank the Foundation of Research Support of the State of São Paulo (FAPESP), which financed this project, and the National Council of Research Development $(\mathrm{CNPq})$ for the fellowship they provided. The authors also thank the Oswaldo Cruz Foundation (Fiocruz) for providing the ATCC 29213 and 25923 strains of S. aureus.

\section{References}

Aguilar B, Iturralde M (2001) Binding of a surface protein of Staphylococcus aureus to cultured ovine mammary gland epithelial cells. Vet Microbiol 82:165-175.

Arciola CR, Baldassarri L, Montanaro L (2001) Presence of icaA and icaD and slime production in a collection of staphylococcal strains from catheter-associated infections. J Clin Microbiol 39:2151-2156.

Arciola CR, Campoccia D, Baldassarri L, Donati ME, Pirini V, Gamberini S, Montanaro L (2005) Detection of biofilm formation in Staphylococcus epidermidis from implant infections. Comparison of a PCR - method that recognizes the presence of ica genes with two classic phenotypic methods. J Biomed Mat Res 76:425-430.

Arciola CR, Campoccia D, Gamberini S, Cernellati M, Donati E, Montanaro L (2002) Detection of slime production by means of an optimized congo red agar plate based on a colorimetric scale in Staphylococcus epidermidis clinical isolates genotyped for ica locus. Biomaterials 23:42334239.

Bannerman TL (2003) Staphylococcus, Micrococcus, and other catalase-positive cocci grow aerobically. In: Murray PR, 
Baron EJ, Pfaller MA, Tenover FC, Yolken RH.(eds). Manual of Clinical Microbiology. Washington DC: American Society for Microbiology, p.384-404.

Baselga R, Albizu I, De La Cruz M, Del Cacho E, Barberan M, Amorena B (1993) Phase variation of slime production in Staphylococcus aureus: implications in colonization and virulence. Infect Immun 61:4857-4862.

Bergey DH, Holt JG (1994) Bergey's Manual of Determinative Bacteriology. Baltimore, Maryland, $350 \mathrm{pp}$.

Bernardi ACA, Pizzolitto EL, Pizzolitto AC (2007) Detection of slime production by coagulase-negative staphylococci isolated from central venous catheter. Rev Cien Farm Apl 28:57-66

Christensen GD, Simpsonv WA, Yonger JJ, Baddor LM, Barrett FF, Melton DM, Beachey EH (1985) Adherence of coagulase-negative Staphylococci to plastic tissue culture plates: a quantitative model for the adherence of Staphylococci to medical devices. J Clin Microbiol 22:996-1006.

Christensen BE (1989) The role of extracellular polysaccharides in biofilms. J Biotechnol 10:181-202.

Costerton JW, Stewart PS, Grenberg EP (1999) Bacterial Biofilms: A Common Cause of Persistent Infections. Science 284:1318-1322.

Cramton SE, Gerke C, Schnell NF, Nichols WW, Gotz F (1999) The intercellular adhesion (ica) locus is present in Staphylococcus aureus and is required for biofilm formation. Infec Immun 67:5427-5433.

Cucarella C, Solano C, Valle J, Amorena B, Lasa I, Penadés JR (2001) Bap a Staphylococcus aureus surface protein involved in biofilm formation. J Bacteriol 183:2888-2896.

Dhanawade NB, Kalorey DR, Srinivasan R, Barbuddhe SB, Kurkure NV (2010) Detection of intercellular adhesion genes and biofilm production in Staphylococcus aureus isolated from bovine subclinical mastitis. Vet Res Commun 34:8189

Freeman DJ, Falkiner FR, Keane CT (1989) New method for detecting slime production by coagulase negative staphylococci. J Clin Pathol 42:872-874.

Godoy MF (1999) Cálculos Estatísticos Básicos para Testes Diagnósticos, Available at: http://www.braile.com.br/DOWNLOAD/TestDiag.xs, Acessed 10 August 2007.
Hensen SM, Pavis MJAMP, Lohuis JACM, Hoog JAM, Poutrel B (2000) Location of Staphylococcus aureus within the experimentally infected bovine udder and the expression of capsular polysaccharide type 5 in situ. J Dairy Sci 83:19661975.

Holmberg O (1973) Staphylococcus epidermidis isolated from bovine milk. Acta Vet Scand 45:1-144.

Jain A, Agarwal A (2009) Biofilm production, a marker of pathogenic potential of colonizing and commensal staphylococci. J Microbiol Methods 76:88-92.

MacFaddin JF (1976) Biochemical Tests for Identification of Medical Bacteria. The Williams \& Wilkins, Baltimore, 312 pp.

Mack D, Rohde H, Dobinsky S, Riedewald J, Nedelmann M, Knoblock JKM, Elsner HA, Feucht HH (2000) Identification of three essential regulatory gene loci governing expression of Staphylococcus epidermidis polysaccharide intercellular adhesin and biofilm formation. Infect Immun 68:3799-3807.

Martineau F, Picard FJ, Roy PH, Ouellette M, Bergeron MG (1998) Species-specif and ubiquitous DNA based assays for rapid identification of Staphylococcus aureus. J Clin Microbiol 36:618-623.

SAS INSTITUTE INC. SAS/STAT. User's Guide: stat. Release 8.1 Edition. Cary, 2001, 1292 pp.

Stepanovic S, Vukovic D, Daki I, Savic B, Vlahovic-Svabic M (2000) A modified microtiter-plate test for quantification of staphylococcal biofilm formation. J Microbiol Methods 40:175-179.

Vasudevan P, Nair MKM, Annamalai T, Venkitanarayanan KS (2003) Phenotypic and Genotypic characterization of bovine mastitis isolates of Staphylococcus aureus for biofilm formation. Vet Microbiol 92:179-185.

Ziebuhr W, Heilmann C, Gotz F, Meyer P, Wilms K, Straube E, Hacker J (1997) Detection of the intercellular adhesion gene cluster (ica) and phase variation in S. epidermidis blood culture strain and mucosal isolates. Infect Immun 65:890-896.

Ziebuhr W, Lossner I, Krimmer V, Hacker J (2001) Methods to detect and analyze phenotypic variation in biofilm-forming staphylococci. Met Enzymol 336:195-205.

All the content of the journal, except where otherwise noted, is licensed under a Creative Commons License CC BY-NC. 